\title{
Support for scientific evaluation of homeopathy stirs controversy
}

Munich. Horst Seehofer, the German health minister, last week gave a positive signal to supporters of homeopathic medicine, telling an international conference in Frankfurt that its success "cannot fundamentally be denied, even though this has often been attempted".

But he also told the meeting, held to celebrate the 200th anniversary of the publication of Samuel Hahnemann's description of the theory of homeopathy, that, like conventional medicines, homeopathic products "should always be able to prove their efficacy". His Hahnemann: described theory remarks coincide with the of homeopathy 200 years ago. completion of a study carried out for the European Commission (EC) which concludes that the efficacy of homeopathic products can indeed be proved using conventional methodology.

Under a directive on homeopathic remedies approved by the European Union in 1992, efficacy does not have to be demonstrated before homeopathic products are marketed. Moreover, homeopaths claim that their therapy cannot be adequately tested through conventional placebocontrolled double-blind clinical trials, as its success depends heavily on the sympathetic attention patients receive from practitioners.

But a year-long pilot study organized and funded by the EC at the request of the European Parliament, intended to indicate whether the EC should fund research into homeopathy, challenges this claim.

The ECU1-million (US\$1.25-million) study, which was formally completed last week, was carried out by a 16-strong group of experts, half sceptics and half proponents of homeopathy. At first, there was an apparently unbridgeable philosophical divide between the two groups. "The two blocks were very confrontational," says Jean-Pierre Boissel, a clinical pharmacologist at the University of Lyons.

But, according to Boissel, the group was surprised to find itself eventually reaching consensus on one of its most important questions, namely that there is no valid reason to exempt homeopathy from normal scientific rules of clinical and preclinical evaluation, provided the individual nature of homeopathic therapy is taken account of.

"We agreed that the efficacy of homeopathy can be tested according to the conventional guidelines for good clinical research," says Boissel. But, he says, "this not been done yet", pointing to the group's analysis of more than 150 published clinical trials, most of which were judged to be of such low quality that no conclusions can be drawn.

The commission now faces the political c decision whether to start European-level clinical triTh as a result of the study.
The issue is certain to be o controversial, given the high level of opposition to homeopathy in pharmacological and medical circles. Flaminio Cattabeni, for example, professor of pharmacology at the University of Milan, Italy, and secretary of the European Federation of Pharmacological

Societies, says that such trials would be "a waste of money".

But the majority of both supporters and opponents of homeopathy favour more scientific investigation of the subject, according to a survey conducted by the group of experts, which polled 1,500 doctors, medical researchers, health administrators, representatives of pharmaceutical and health insurance companies and politicians .

Homeopathy has an uneven pattern of acceptance in Europe. While it has never been widely accepted in Scandinavia and Britain, there is a high demand for homeopathic products in France, Italy and Germany. In Germany, insurance companies are even willing to pay for homeopathic treatment, despite steadfast opposition from the German scientific community.

But, as Ulrich Schwabe, professor of pharmacology at the University of Heidelberg, points out, insurance companies may be swayed by the fact that homeopathic products are relatively cheap. A final report of the findings of the EC group will be to the parliament before the end of the year.

Alison Abbott \& Gabor Stiegler

\section{California doubles research tax credit}

San Francisco. California's state legislature is trying to boost industry's spending on university research by approving significant increases in tax incentives for both basic and clinical research. The bill including the increases was approved by the legislature in early September, and is expected to be signed by Peter Wilson, the state governor, in the near future.

The bill applies to companies investing in research at a Californian university, research institute or university hospital. The state tax credit would double, from 12 to 24 per cent of eligible expenditures for basic research, and increase from 8 to 12 per cent of applied research spending. The credit will apply to any spending increases above a company's previous three-year average.

Enthusiastic support for the increased tax incentives has come from California's biotechnology industry. William Bold, director of public policy for the California Healthcare Institute, a lobby group for the biotechnology and pharmaceutical industry, says the credits are likely to inspire companies to put more money into basic research at universities and university hospitals in the state.

For the purposes of the law, 'basic' research is broadly defined to include both exploratory research and clinical tri- als at university hospitals, which had not previously been eligible for tax credits. The credit may help companies to pursue basic research beyond a core of three or four lead products, Bold says.

Legislators hope that the increased credit - which will be higher than the tax incentives in any other state - will encourage biomedical companies to remain in California.

In the past, the University of California has not been welcoming to private investors, according to David Nagler, director of state affairs for Genentech. He said the company hopes the university will use the credit to attract more contracts for basic and clinical research. The state franchise tax board has estimated that Californian biotechnology companies spend almost $\$ 20$ million on university clinical trials within the state. With the tax credit, that figure should double, the board said. "I hope that's wildly conservative," Nagler added.

The use of tax incentives to boost industry research spending remains controversial. Nevertheless, a report prepared by the accountants KPMG Peat Marwick LLP concluded that a $\$ 1$ reduction in after-tax cost of research creates about $\$ 1$ of additional spending initially, and $\$ 2$ in the long term. Sally Lehrman 